\title{
Case Studies of Ergonomic Interventions in Automotive Parts Distribution Operations
}

\author{
Sheryl S. Ulin ${ }^{1,2}$ and W. Monroe Keyserling ${ }^{1}$
}

Ergonomic job analysis, intervention design, and intervention implementation are essential components of an ergonomics program designed to reduce worker exposure to risk factors associated with musculoskeletal disorders. As part of a 4-year study to reduce overexertion injuries in the service parts division of a major automaker, intervention case studies were identified that could be used at multiple facilities across the division. Interventions were developed and implemented. The three case studies include 1) self-elevating powered vehicle for transporting parts throughout the facility and for reaching to high bin locations; 2) lift and tilt pallet jacks for packing small parts into large bin-like containers; and 3) single-level telescoping conveyor used for delivering hand-held totes for subsequent sorting operations. Several analysis methods were used to assess worker exposure before and after intervention implementation (biomechanical analysis, posture analysis, worker interviews, and activity analysis). Following implementation, a decrease in exposure to risk factors for musculoskeletal disorders was documented. Worker interviews revealed acceptance and agreement that risk factors associated with the targeted tasks were reduced. Each case study includes a description of the implementation hurdles and can serve as both primary and secondary prevention of musculoskeletal disorders. Future work should document worker health and/or symptom changes as well as changes in risk factor exposure.

KEY WORDS: ergonomics; intervention; musculoskeletal disorder; job analysis.

\section{BACKGROUND}

Work-related musculoskeletal disorders (MSDs) currently account for approximately one-third of all occupational injuries and illnesses reported by U.S. employers, are the largest job-related injury and illness problem in the nation, and are estimated to cost $\$ 15$ 20 billion per year (not including indirect costs) (1). In 2001, 216,400 cases of disorders associated with repeated trauma were reported (2). For cases involving days away from work in 2001, 42,679 back pain cases, 26,794 carpal tunnel syndrome cases, and 14,124 tendonitis cases were reported (2). The highest incidence rates associated with repeated trauma are

\footnotetext{
${ }^{1}$ Center for Ergonomics, The University of Michigan, Ann Arbor, Michigan.

${ }^{2}$ Correspondence should be directed to Sheryl S. Ulin, PhD, CPE, Senior Research Associate Engineer, Center for Ergonomics, The University of Michigan, 1205 Beal - IOE Bldg., Ann Arbor, Michigan 48109-2117; e-mail: sheryl.ulin@umich.edu.
} 
found in industries such as meat packing, motor vehicles, motor vehicle accessories, apparel trimmings, and ship building, among others (2).

To reduce the incidence of musculoskeletal disorders, employers have been developing interventions to reduce worker exposure to risk factors of musculoskeletal disorders through a variety of methods. Westgaard et al. (3) classified these interventions as:

1) Mechanical exposure interventions (reducing worker exposure to risk factors such as excessive repetition, high force or awkward posture) $(4,5)$.

2) Production system interventions (changes to the production system and/or the company organizational culture often through a participatory ergonomics program) (6-8).

3) Modifier interventions (workers are put in a better position to address existing job demands through health education, exercise, and other types of training) (9-11).

A study was conducted within a large U.S. automotive manufacturer to better understand the relationship between musculoskeletal injuries and exposure to ergonomic risk factors in the company's service parts distribution division. One part of the study focused on developing case studies to evaluate the effectiveness of ergonomic interventions in reducing exposures to risk factors. This paper describes three of the case studies. Another study goal was to develop a process for identifying specific work locations and activities where physical demands placed workers at increased risk of sustaining an overexertion injury and this is described elsewhere (12). The case studies presented in this paper were chosen based on:

- high levels of exposure to risk factors associated with musculoskeletal disorders (e.g. severe torso flexion and/or estimated low back disc compression force above recommended guidelines),

- potential widespread use by many workers and other warehouses (i.e. the same intervention could be applied to many other work situations throughout the company), and

- funding availability (i.e. facility budgets for capital improvements as well as budget availability for "ergonomics").

These case studies are the result of working with ergonomic teams, engineers, management, and researchers. They reflect the production realities of most manufacturing systems but they do not reflect a "gold standard" in research intervention design.

\section{STUDY SETTING}

To provide repair parts to dealerships quickly, automotive companies maintain a network of parts distribution centers that are typically organized as a two-tier system. Regional centers fill orders for replacement parts from the service departments of local dealers. National centers obtain replacement parts in bulk from original equipment manufacturers and replenish the stock in the regional centers as needed. The service parts distribution system in our study consisted of 15 regional centers and 4 national centers located throughout the U.S (12).

Manual materials handling activities (lifting, carrying, pushing, etc.) were common in both the regional and national centers. The national centers also required repetitive hand 
operations such as assembling repair kits from small components (e.g., gaskets, washers, springs, etc.), and hand-packing pallet loads of small replacement parts (e.g., brake drums, small electric motors, mirrors, etc.) into individual cartons (12). These operations were typically done in batches and the specific product handled could vary day-to-day or even hour-to-hour.

Four sources of information were combined to identify opportunities for ergonomic intervention including reviews of injury records, ergonomic assessments of selected operations, facility walk-throughs by ergonomic experts, and input from facility ergonomic committees (12). Review of injury records covering a 3-year period revealed that overexertion injuries were common primarily due to manual materials handling activities and manual picking tasks. The average rate of overexertion/overuse musculoskeletal disorders in the parts distribution division was 13.1 incidents per 100 worker-years. Ergonomic evaluations were performed to measure ergonomic stresses for selected work activities suggested by the injury record analysis. In addition, ergonomics professionals toured the facilities to understand the ergonomic challenges, and joint labor-management committees from each of the distribution centers identified their top 10 ergonomic concerns.

\section{ANALYSIS METHODS}

Several analysis methods were used to quantify the exposures to risk factors for each case study:

1. Biomechanical analysis of L5/S1 disc compression when pulling and lifting (Case studies 2 and 3).

2. Biomechanical analysis of torso and shoulder strength demands when pulling and lifting (Case studies 2 and 3).

3. Posture analysis of the trunk and shoulders (Case studies 1, 2, and 3).

4. Worker interviews (Case studies 1, 2, and 3).

5. Activity analysis (Case study 1).

The analyses were completed before and after the interventions were implemented. Appropriate methods were selected to evaluate each work task.

\section{Biomechanical Analysis of L5/S1 Disc Compression and Joint Strength Requirements}

The University of Michigan Three-Dimensional Static Strength Prediction Program ${ }^{\mathrm{TM}}$ (3DSSPP ${ }^{\mathrm{TM}}$ ) (13) was used to estimate the back compression force and the joint strength capabilities associated with a single exertion (e.g. lift, push, pull). The model inputs included anthropometry, hand force exerted, and work posture. Output from the model included back compression force and joint strength requirements compared to capabilities for each analyzed task. The predicted back compression force and strength capabilities could then be compared to NIOSH guidelines.

Two points have been defined by NIOSH for categorizing spinal compression forces, the design limit, and upper limit. The NIOSH guidelines include:

- Back compression design limit (BCDL): $3425 \mathrm{~N}$ of back compression force

- Back compression upper limit (BCUL): $6361 \mathrm{~N}$ of back compression force 
These points were identified by the committee advising NIOSH on the 1981 and 1991 NIOSH lifting equation (14) and were chosen based on studies that examined the relationship between low back pain and predicted static back compression force. Additionally, data from laboratory cadaver studies were also reviewed to determine disc end-plate failure due to compression force. Workers performing lifting jobs with a predicted compressive force greater than $3400 \mathrm{~N}$ had a $40 \%$ higher incidence rate of low back pain than did workers in jobs with predicted compressive forces below that level (15).

The $3 \operatorname{DSSPP}^{\mathrm{TM}}$ (13) was also used to analyze the joint strength capabilities of a single lift. On the basis of the inputs of gender, posture, and force applied (pull or lift), the percentage of the population with the capability at various joints was computed. The NIOSH strength guidelines are listed below.

- Strength design limit (SDL): Over 99\% of males and over $75 \%$ of females have the strength capability to complete the task.

- Strength upper limit (SUL): $\quad 25 \%$ of males and less than $1 \%$ of females have the strength capability to complete the task.

These criteria guidelines were described by NIOSH in the "Work Practices Guide for Manual Lifting" (16). The guide described various methods for reducing the risk associated with manual materials handling tasks. In addition, NIOSH identified the strength criteria above as a method to reduce risk of worker injury while performing lifting tasks. Specifically, they classified jobs as representing nominal risk of injury to industrial work populations when the strength and back compression were below the design limits.

The biomechanical analyses were used to determine the maximum weight of items to be lifted in order to stay at or below the back compression and strength design limits. Worker posture was determined on the basis of the physical dimensions of the workplace (i.e. where the hands were located) and videotape of workers performing the task. Fiftieth percentile male and female anthropometry were used in the analyses since a wide variety of workers performed these jobs. The analyses were completed for weights of the load ranging from 2.3 to $22.7 \mathrm{~kg}$. The back compression force and joint strength capabilities were then compared to the design criterion to determine when these values were greater than the design criterion for the specified load, posture, and anthropometry. These analyses were completed on the basis of the hand locations and postures required for completing the tasks both before and after the interventions were implemented. This allowed comparison of the weight of the load that was below the design criterion for both conditions.

\section{Posture Analysis}

A computerized posture analysis system was used to measure the amount of time spent in neutral and nonneutral postures (17). Torso posture was classified into four categories: 1) neutral, 2) mild flexion (20-45 forward bending), 3) severe flexion ( $>45^{\circ}$ forward bending), and 4) twisted/bent (more than $20^{\circ}$ of axial twisting or lateral bending). Shoulder posture was classified into three categories: 1) neutral, 2) mild elevation $\left(45-90^{\circ}\right.$ angle between upper arm and torso) and 3) severe elevation ( $>90^{\circ}$ angle between upper arm and torso). Various work tasks were videotaped at the work site and were used to determine 
the amount of time the torso and shoulder were in the various posture categories. These analyses were completed before and after the interventions were implemented to compare the amount of time workers spent in neutral and nonneutral positions.

\section{Worker Interviews}

The worker interview collected demographic information from the participant and then focused on the physical demands of the job he/she regularly performed. During the interview, workers were asked to assess their perception of the physical job attributes, most physically demanding work tasks, seasonal variations in physical stress, and body discomfort. To assess workers' job perception, workers were asked to respond to a statement by using a 10-point rating scale with verbal anchors at 0 and 10 and then describe the reasoning for their response. For example, workers were asked to rate the "torso/back position while performing this job" where $0=$ very comfortable posture and $10=$ very uncomfortable posture. The worker ratings before and after the interventions were implemented were compared using $t$ tests (18) to determine if a significant change in worker perceptions $(p<$ 0.10 ) had occurred.

\section{Activity Analysis}

A computerized activity analysis system was used to quantify the amount of time that workers spent performing various work tasks. Work tasks that were identified for this activity analysis included standing on the floor, walking, pushing a manually operated vehicle (e.g. pallet jack), climbing, working from an elevated position, and standing or driving a vehicle. This is a modification of the posture analysis software described above (17). This analysis was completed before and after the interventions were implemented to compare the amount of time workers spent performing various work tasks.

\section{CASE STUDY 1: SELF-ELEVATING VEHICLE}

\section{Motivation for Intervention}

Traditionally, workers within the distribution centers stocked and picked parts from racks and bins that ranged in height from floor level to approximately $3.6 \mathrm{~m}$. The vehicles used for transporting parts around the warehouse and for reaching the high-bin locations have generally been manually pushed ladder carts. The primary ergonomic concerns when stocking and picking using the ladder cart included (see Figs. 1 and 2):

1) pushing the ladder cart to the various rack locations,

2) shoulder elevation and extended reaches into the bins to reduce the actual number of steps climbed on the ladder (see Fig. 1), and

3) climbing up and down on the equipment (50\% of the time workers have objects in their hand while climbing) (see Fig. 2). This was also a safety issue of increased risk of falling when climbing with only one hand on the ladder railing. 


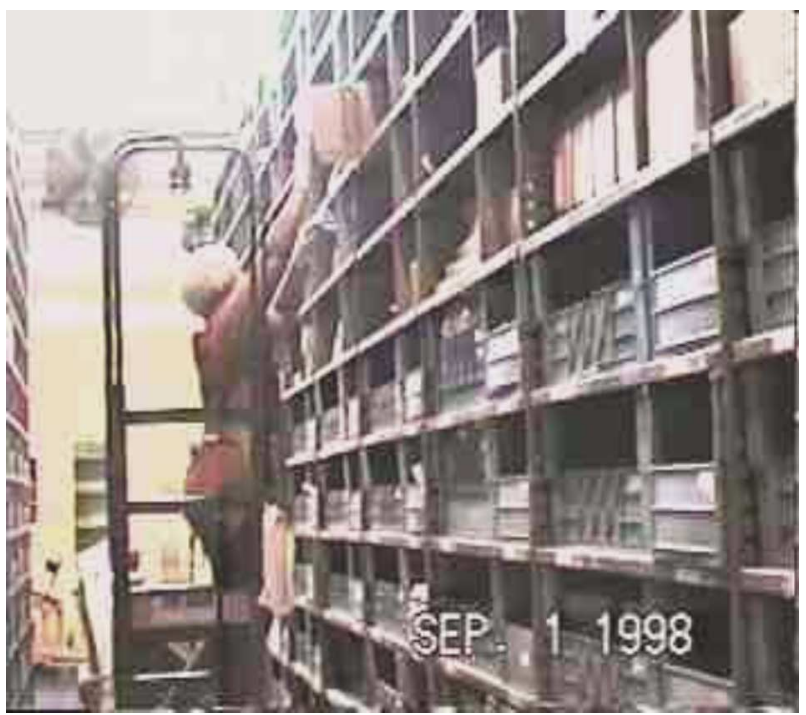

Fig. 1. Shoulder elevation associated with positioning boxes in bins instead of climbing additional steps on the ladder.

\section{Description of Intervention}

Ladder climbing, pushing carts, and shoulder elevation can be eliminated or reduced through the use of a motorized vehicle capable of both horizontal and vertical movement. Five self-elevating vehicles were purchased for three different centers. This vehicle was

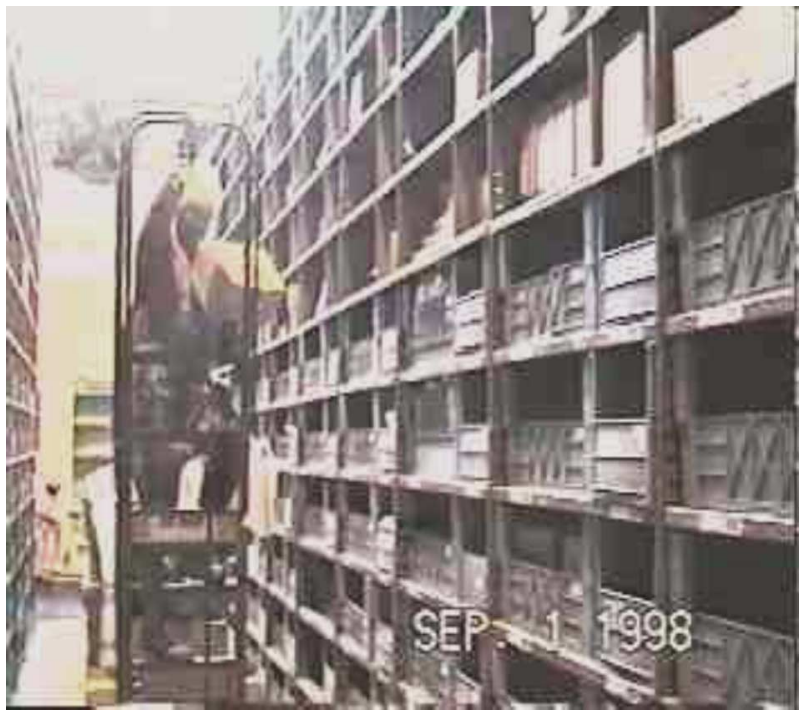

Fig. 2. Workers must climb up and down the ladder with boxes or parts in one hand. 


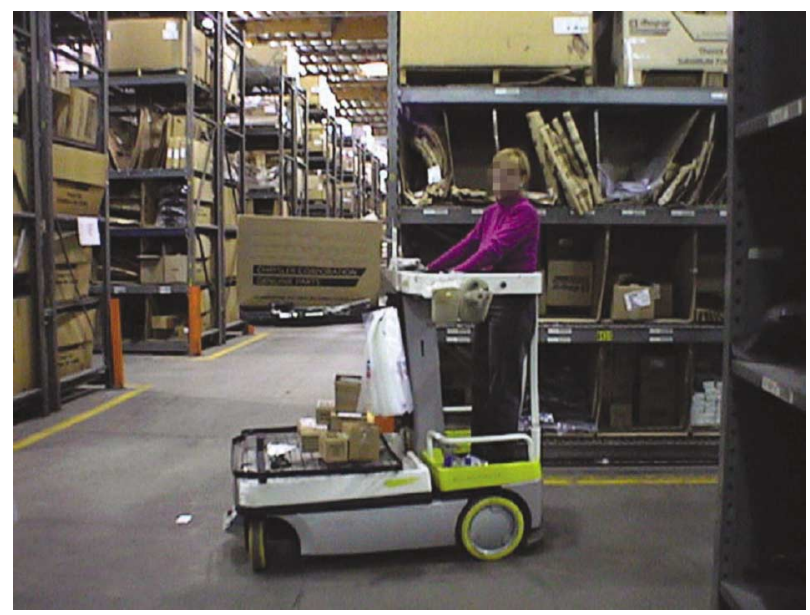

Fig. 3. Lowest vertical position of the self-elevating vehicle (used for horizontal movement).

battery powered, traveled at a speed of $6.4 \mathrm{~km} / \mathrm{h}$, and the platform raised to a vertical height of $4.1 \mathrm{~m}$ (see Figs. 3 and 4). The original design of the vehicle was modified slightly by the manufacturer to provide a larger tray for storing product.

\section{Summary of Intervention Effectiveness}

\section{Elimination of Manual Horizontal Pushes}

Workers needed to push ladder carts throughout the parts distribution centers to transfer items to the appropriate bin locations. Biomechanical analyses of the push force showed

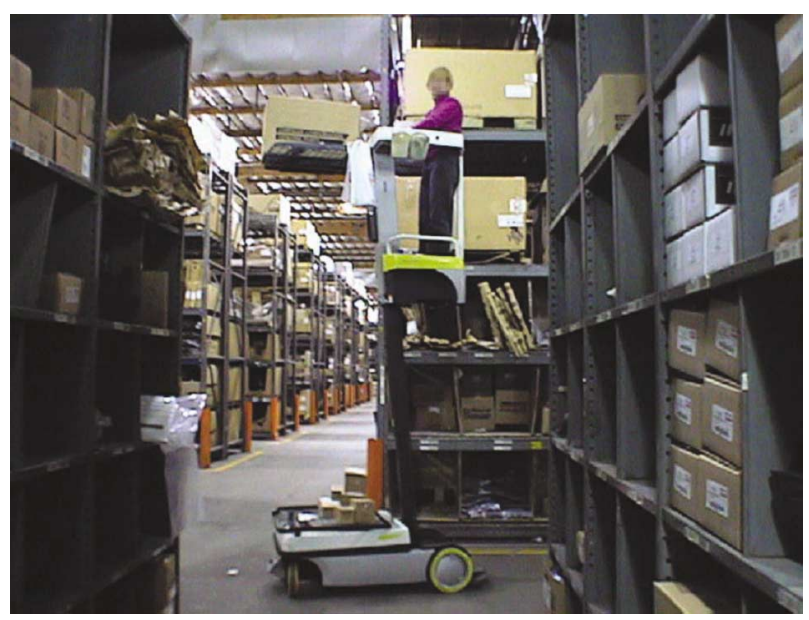

Fig. 4. Elevated vertical position of the self-elevating vehicle (used for stocking and picking). 
Table I. Summary of Exposure Data for Case Study 1, Self-Elevating Vehicle

\begin{tabular}{|c|c|c|}
\hline & $\begin{array}{l}\text { Before intervention } \\
\text { was implemented }\end{array}$ & $\begin{array}{l}\text { After intervention was } \\
\text { implemented }\end{array}$ \\
\hline \multicolumn{3}{|c|}{ Weight of the load (cart) pushed below design criterion based on } \\
\hline Back compression force & $\begin{array}{l}\text { All push forces } \\
\text { evaluated }\end{array}$ & $\begin{array}{l}\text { No pushing } \\
\text { required }\end{array}$ \\
\hline Strength capability & $\begin{array}{l}\text { All push forces } \\
\text { evaluated }\end{array}$ & $\begin{array}{l}\text { No pushing } \\
\text { required }\end{array}$ \\
\hline \multicolumn{3}{|l|}{ Percent of time in } \\
\hline Neutral torso postures & $86 \%$ & $91 \%$ \\
\hline Nonneutral torso postures & $14 \%$ & $9 \%$ \\
\hline Neutral shoulder postures & $77.6 \%$ & $88 \%$ \\
\hline Nonneutral shoulder postures & $22.4 \%$ & $12 \%$ \\
\hline \multicolumn{3}{|l|}{ Percent of time performing } \\
\hline Climb/work from ladder & $33 \%$ & $0 \%$ \\
\hline Push vehicle & $6 \%$ & $0 \%$ \\
\hline \multicolumn{3}{|l|}{ Worker perceptions } \\
\hline $\begin{array}{l}\text { Overall assessment of the required } \\
\text { physical effort/stress to perform } \\
\text { this job. }(0=\text { very easy work; } 10=\text { very } \\
\text { hard work })\end{array}$ & $4.0 \pm 1.4$ & $4.7 \pm 3.3$ \\
\hline $\begin{array}{l}\text { Torso/Back position while } \\
\text { performing this job }(0=\text { very } \\
\text { comfortable posture; } 10= \\
\text { very uncomfortable posture })\end{array}$ & $6.7 \pm 1.5$ & $3.0 \pm 3.5^{*}$ \\
\hline $\begin{array}{l}\text { Pushing/pulling work objects } \\
\quad(0=\text { very easy work; } 10= \\
\text { very hard work })\end{array}$ & $5.3 \pm 0.6$ & $3.6 \pm 3.9$ \\
\hline
\end{tabular}

${ }^{*} p<0.10$ for two-tailed $t$ test.

that the L5/S1 disc compression force was well below $3425 \mathrm{~N}$ and virtually all adult males and females possessed the torso and shoulder strength capabilities to push the ladder cart. Although pushes were not found to be biomechanically stressful, the self-elevating vehicle eliminated the activity of pushing the ladder cart (see Table I).

\section{Torso Posture}

The self-elevating vehicle was not expected to improve trunk posture since workers were still required to reach periodically to the lowest bin levels. However, small improvements were observed (see Table I). Predominantly neutral torso postures were observed when using all vehicles. Severe torso flexion (forward bending) was observed in all cases when workers picked or stocked parts from the lower shelves and this was not affected by the introduction of the self-elevating vehicle. Severe torso flexion was also observed when workers positioned tickets on the sides of the ladder cart, and this was eliminated with the self-elevating vehicle.

\section{Shoulder Posture}

When using the powered ladder truck or ladder cart, nonneutral postures were observed $22.4 \%$ of the time. Nonneutral postures occurred when the arms were extended forward 


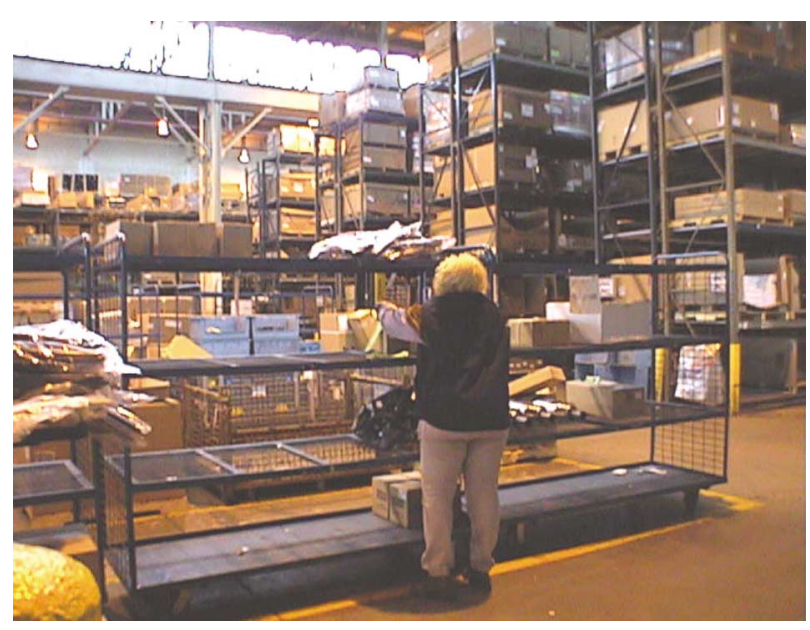

Fig. 5. Shoulder elevation to retrieve items from cart to load the selfelevating vehicle (not affected by intervention).

and when the shoulder was raised to pick or place objects in bins or to scan bar codes at overhead bin locations (see Fig. 1). The self-elevating vehicle raised workers vertically to the appropriate bin location for picking or stocking parts (see Fig. 4). There was a decrease in shoulder elevation while using the self-elevating vehicle for picking and stockkeeping. Overall, the self-elevating vehicle reduced the amount of time the shoulder was in nonneutral postures to $12 \%$ of the time, roughly one-half of the duration of nonneutral posture with the ladder cart (see Table I). Elevated arms were observed while loading the self-elevating vehicle; both while reaching to the back of the cart to retrieve items (not affected by the intervention) and when stacking items on the self-elevating vehicle (see Figs. 5 and 6).

\section{Whole Body Activity Analysis}

Workers were at increased risk of experiencing a "fall from elevation" accident when climbing, descending, or standing on ladders. The risk of a fall may increase if the worker cannot use both hands to grasp the ladder rails. An analysis of work activities showed that during stocking and picking operations with the ladder cart and powered ladder truck, workers spent approximately one-third of the time working on ladders (see Table I). This was reduced to zero with the self-elevating vehicle. When using the ladder cart for stocking and picking, workers spent $6 \%$ of the time pushing the ladder cart. This was reduced to zero with the self-elevating vehicle.

\section{Worker Interviews}

The following findings were obtained from interviews with three workers who used the powered ladder truck or ladder cart and five employees who used the self-elevating vehicle (see Table I). 


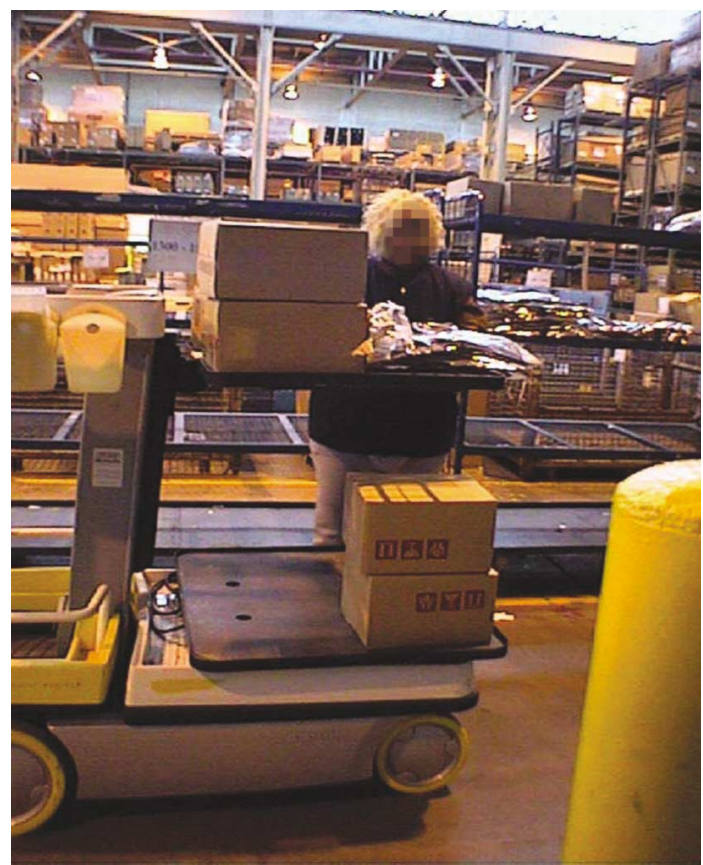

Fig. 6. Boxes stacked higher than shoulder height on the selfelevating vehicle which would lead to shoulder elevation.

- Workers identified climbing up and down ladders and picking from the lowest shelves as the most physically demanding part of their job.

- There was a marginally significant decrease $(p<0.10)$ in worker evaluations of torso postural strain when using the self-elevating vehicle.

- There was a nonsignificant decrease in worker evaluations of pushing/pulling demands and shoulder postural strain when using the self-elevating vehicle.

\section{Implementation Hurdles/Fine Tuning}

The self-elevating vehicle was customized by workers because the original design did not have room for their tickets or plastic bags. Additional worker criticisms were that the self-elevating vehicle moved too slowly horizontally and that the part tray was too small. During self-elevating vehicle testing, the picking/stockkeeping sequence was not modified to minimize vehicle horizontal movement. There are opportunities to optimize horizontal and vertical movement sequencing of the self-elevating vehicle.

\section{Discussion}

The use of the self-elevating vehicle for stocking and picking eliminated ladder climbing and pushing ladder carts, and reduced the amount of walking, reaching above shoulder height, and torso forward bending. Consequently, both mobility issues and safety concerns 
associated with climbing, walking for extended periods, and pushing ladder carts were addressed. In addition, workers felt that the self-elevating vehicle reduced the physical stress associated with their job. The self-elevating vehicle should provide benefits to all workers who pick or stock from high locations and should also accommodate persons with ladder climbing or walking limitations. To address the major worker criticism, new algorithms that minimize horizontal travel distance between the pick/stock locations can be developed and used once all workers in a specific area are using the self-elevating vehicle.

\section{CASE STUDY 2: LIFT AND TILT PALLET JACK}

\section{Motivation for Intervention}

At the end of kit assembly lines, workers packed corrugated cases and/or plastic bags of varying size and weight into "triwalls," large bin-like containers constructed of heavy corrugated cardboard. When placed on the floor, a triwall was approximately $91.4-\mathrm{cm}$ high, 119.4-cm long, and 104.1-cm deep. Triwalls were frequently placed on pallets to facilitate the use of materials handling equipment such as pallet jacks and forklift trucks. This increased the height of the container by $10.2-12.7 \mathrm{~cm}$.

The primary ergonomic concern when packing triwalls occurred when employees performed low or far reaches in order to position an object in the bottom of an empty triwall. The combination of low working height and a far horizontal reach created high levels of biomechanical and postural strain at the lower back (see Fig. 7).

\section{Description of Intervention}

One intervention that was identified was a lift/tilt pallet jack. This device moved pallets loaded with triwalls in and out of packing locations, and raised and tilted the triwalls

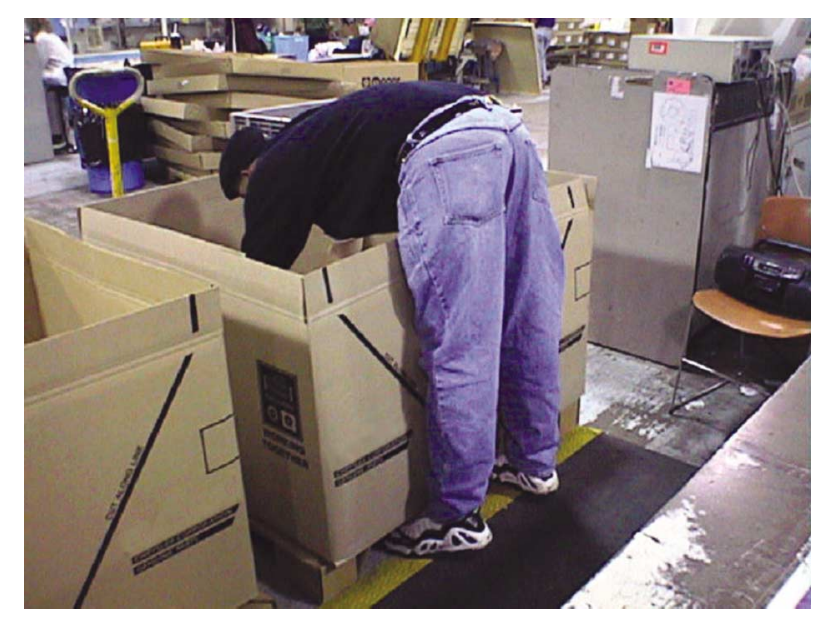

Fig. 7. Placing corrugated cases into the bottom of a triwall is associated with awkward trunk postures. 


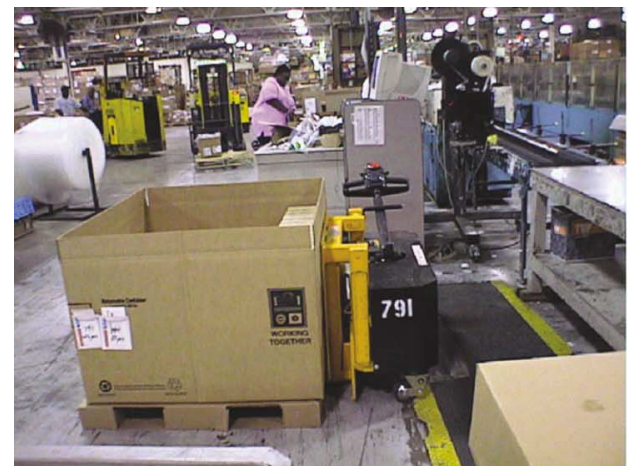

(a)

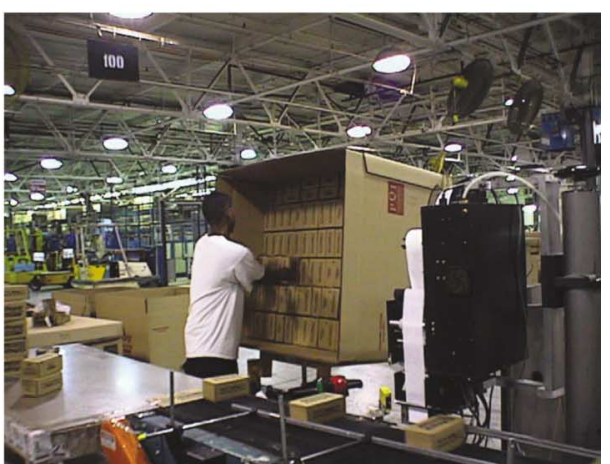

(b)

Fig. 8. Lift/tilt pallet jack - a combination pallet jack and lift/tilt device. Panel 2(a) shows the lift/tilt pallet jack positioned under a triwall on the floor. Panel 2(b) shows the lift/tilt pallet jack with a raised triwall.

(maximum tilt of $90^{\circ}$ ) (see Fig. 8). This device raised the triwall lower edge to a vertical height of $78.7 \mathrm{~cm}$ from the floor, with a maximum vertical height of $185.4 \mathrm{~cm}$ (top of the triwall). Workers reached over the lift/drive mechanism to pack the triwall, creating a maximum horizontal distance of approximately $101.6 \mathrm{~cm}$. Lift/tilt tables were also considered but were found to be infeasible due to the need to move triwalls with pallet jacks frequently.

\section{Summary of Intervention Effectiveness}

\section{Low Back}

Because of the configuration of the lift/tilt pallet jack, the maximum ergonomic benefits were realized when it was used in the "full elevation" position where the triwall was raised $78.7 \mathrm{~cm}$ off the floor and tilted $90^{\circ}$ toward the operator. Although it was possible to use the pallet jack in an intermediate lift/tilt configuration, obstructions inherent to the pallet jack hardware increased horizontal reach distances and negated potential ergonomic benefits (see Fig. 9).

The lift/tilt pallet jack provided significant reductions in biomechanical stresses to the trunk when packing at the front and middle of the triwall (see Table II). For example:

- With the triwall on the floor, compressive forces at the L5/S1 disc exceeded NIOSH back compression design limit when part weight reached approximately $7.3 \mathrm{~kg}$. With the triwall on the lift/tilt pallet jack, NIOSH recommendations were not exceeded for parts up to $18.2 \mathrm{~kg}$.

- With the triwall on the floor, $10 \%$ of the male population and $25 \%$ of the female population would have difficulty handling loads more than $9.1 \mathrm{~kg}$ at the middle of the triwall based on strength capability in the low back. With the triwall on the lift/tilt pallet jack, the load weight could be increased to $13.6 \mathrm{~kg}$ without creating substantial strength demands on the low back.

The lift/tilt pallet jack provided only marginal reductions in biomechanical stresses to the trunk. The benefits occurred when packing in the front and middle zones of the triwall. 


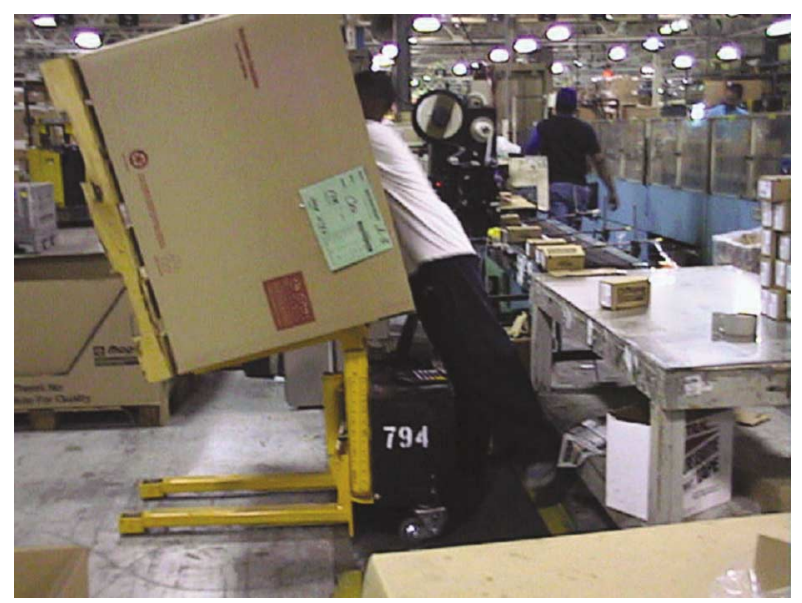

Fig. 9. Lift/tilt pallet jack in intermediate position.

Because of long horizontal reach requirements when packing at the back of the triwall, part weight should not exceed $7.3 \mathrm{~kg}$.

The lift/tilt pallet jack provides significant reductions in trunk postural stress. With the triwall on the floor, workers used severe trunk flexion (forward bending more than $45^{\circ}$ ) during $8 \%$ of the work cycle. With the triwall on the lift/tilt pallet jack, severe flexion was completely eliminated. Placing the triwall on the lift/tilt pallet jack allowed the worker to use a neutral posture $95 \%$ of the work cycle, compared to $84 \%$ of the cycle when the triwall was on the floor (see Table II).

Table II. Summary of Exposure Data for Case Study 2, Lift and Tilt Pallet Jack

\begin{tabular}{|c|c|c|}
\hline & $\begin{array}{l}\text { Before intervention } \\
\text { implemented }\end{array}$ & $\begin{array}{l}\text { After intervention was } \\
\text { implemented }\end{array}$ \\
\hline \multicolumn{3}{|l|}{ Weight of load lifted below design criterion based on } \\
\hline Back compression force & $7.3 \mathrm{~kg}$ & $7.3 \mathrm{~kg}$ \\
\hline Back strength capability & $9.1 \mathrm{~kg}$ & $13.6 \mathrm{~kg}$ \\
\hline Shoulder strength capability & $15.5 \mathrm{~kg}$ & $8.2 \mathrm{~kg}$ \\
\hline \multicolumn{3}{|l|}{ Percent of time in } \\
\hline Neutral torso Postures & 84 & 95 \\
\hline Nonneutral torso postures (more than $45^{\circ}$ flexion) & 8 & 0 \\
\hline Neutral shoulder postures & 95 & 84.5 \\
\hline Nonneutral shoulder postures (more than $90^{\circ}$ flexion) & 1 & 10.5 \\
\hline \multicolumn{3}{|l|}{ Worker perceptions } \\
\hline $\begin{array}{l}\text { Overall assessment of the required physical effort/stress to } \\
\text { perform this job. }(0=\text { very easy work; } 10=\text { very hard } \\
\text { work })\end{array}$ & $4.0 \pm 1.8$ & $3.9 \pm 2.0$ \\
\hline $\begin{array}{l}\text { Torso/Back position while performing this job }(0=\text { very } \\
\quad \text { comfortable posture; } 10=\text { very uncomfortable posture })\end{array}$ & $5.3 \pm 2.9$ & $1.4 \pm 1.7 *$ \\
\hline $\begin{array}{l}\text { Shoulder and upper arm position while performing this job } \\
(0=\text { very comfortable posture; } 10=\text { very uncomfortable } \\
\text { posture })\end{array}$ & $4.2 \pm 2.3$ & $3.0 \pm 2.6$ \\
\hline
\end{tabular}

${ }^{*} p<0.05$ for two-tailed $t$ test. 


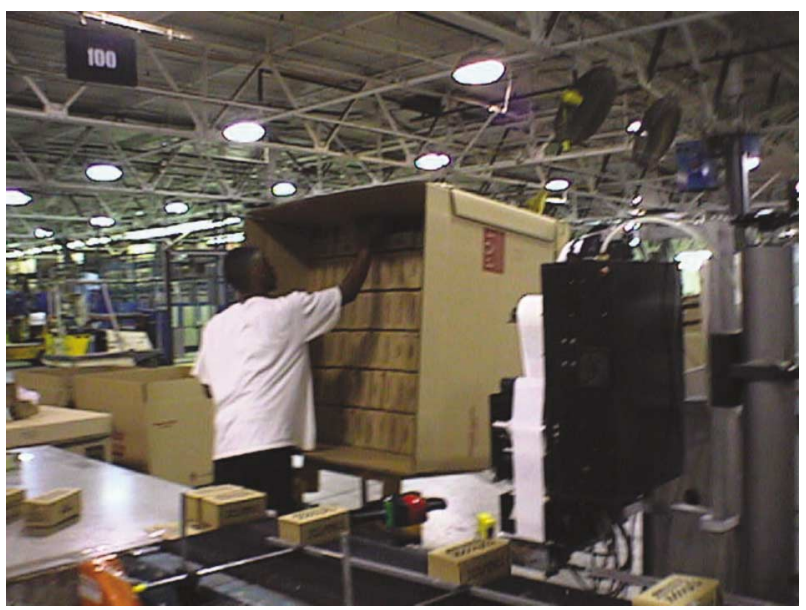

Fig. 10. Workers must elevate their shoulders when working with the lift/tilt pallet jack in the fully elevated position.

\section{Shoulder}

Reductions in biomechanical and postural stresses affecting the lower back came at the cost of increases in biomechanical and postural stresses affecting the shoulder (see Fig. 10 and Table II). This was due to the fact that workers must raise the shoulders in order to reach to higher vertical locations when the triwall was on the lift/tilt pallet jack. For example:

- With the triwall positioned on the floor, workers used a neutral shoulder posture (elevation less than $45^{\circ}$ ) during $95 \%$ of the work cycle and severe shoulder elevation (more than $90^{\circ}$ ) occurred for only $1 \%$ of the work cycle. With the triwall on the lift/tilt pallet jack, neutral shoulder posture was reduced to $84.5 \%$ of the work cycle, while severe flexion was required for $10.5 \%$ of the cycle.

- With the triwall positioned on the floor, part weights up to $15.5 \mathrm{~kg}$ in the middle of the triwall could be handled by most of the female population $(75 \%)$ based on shoulder strength, and part weights up to $18.2 \mathrm{~kg}$ could be handled by most of the male population $(>90 \%)$. With the triwall positioned on the lift/tilt pallet jack, most of the female population could handle weights of only $8.2 \mathrm{~kg}$ based on shoulder strength while most of the male population could handle weights of only $13.6 \mathrm{~kg}$.

\section{Worker Interviews}

Twelve workers who loaded triwalls positioned on the floor and five who used the triwall on the lift/tilt pallet jack were interviewed. There was a significant decrease $(p<0.05)$ in worker perceptions of trunk postural strain when working with the triwall on the lift/tilt pallet jack (see Table II). 


\section{Implementation Hurdles/Fine Tuning}

Traditional lift/tilt tables may have an advantage over the lift/tilt pallet jack if they 1) can be configured with no horizontal obstructions, and 2) can be configured so that workers can adjust the lift height and tilt angles continuously over the entire range. However, traditional lift/tilt tables did not prove feasible at the parts distribution centers with packing operations due to the need to move triwalls frequently with pallet jacks.

\section{Discussion}

The lift/tilt pallet jack eliminated the worst-case scenario of long horizontal reaches to low vertical locations. Consequently, the biomechanical and postural stresses while packing triwalls were reduced. Because of the configuration of the lift/tilt pallet jack, the maximum ergonomic benefits were realized when it is used in the "full elevation" position where the triwall was raised $78.7 \mathrm{~cm}$ off the floor and tilted $90^{\circ}$ toward the operator. Although it was possible to use the lift/tilt pallet jack in an intermediate lift/tilt configuration, obstructions inherent to the lift/tilt pallet jack hardware increased horizontal reach distances and reduced potential ergonomic benefits. For this reason, it was suggested that the lift/tilt pallet jack be used only in the full elevation position when packing triwalls.

\section{CASE STUDY 3: TELESCOPING CONVEYOR}

\section{Motivation for Intervention}

Within regional distribution centers, fast moving small parts were picked and placed into totes for delivery to individual dealers. When a route pick was completed, these totes left the picking area via a two-level output conveyor. Workers had to unload the totes from the output conveyor so they could be consolidated and packed into trucks for delivery to the dealer.

The primary ergonomic concern when pulling and lifting totes from the carousel output conveyor occurred when employees bent forward to transfer totes from the low level of the conveyor (vertical height of $22.9 \mathrm{~cm}$ ). This created high levels of biomechanical and postural strain at the lower back (see Fig. 11).

\section{Description of Intervention}

Biomechanical and postural strain was reduced by eliminating the low level of the output carousel conveyor. An 81.3-cm high, single-level telescoping conveyor was introduced (see Fig. 12).

\section{Summary of Intervention Effectiveness}

\section{Low Back}

Low back compression forces exceeded the NIOSH criterion of $3425 \mathrm{~N}$ for lifting totes as light as $4.5 \mathrm{~kg}$ from the low level of the old conveyor. Compression forces when working 


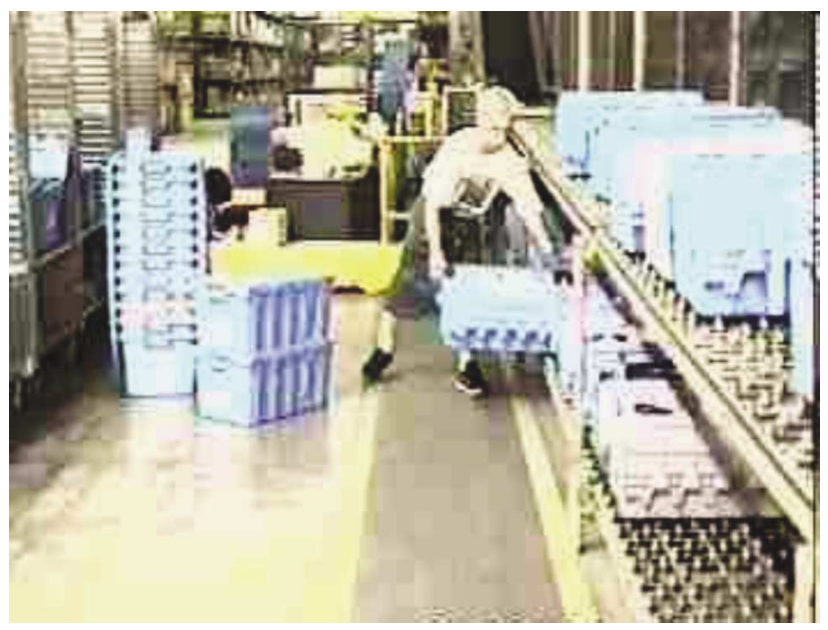

Fig. 11. Picking up a tote from the low level of the carousel output conveyor was associated with awkward trunk postures.

at the high level of the old conveyor (vertical height of $94 \mathrm{~cm}$ ) and the new single-level conveyor (vertical height of $81.3 \mathrm{~cm}$ ) were below the NIOSH threshold for all tote weights analyzed (0-22.7 kg). Significant reductions of low back biomechanical stress occurred with the use of the new single-level telescoping conveyor (see Table III).

In addition, trunk postural stresses were also reduced when workers used the new single-level conveyor. Workers no longer bent forward to pick up totes from the low level of the conveyor. Neutral trunk postures were observed for $96 \%$ of the time when workers used the new single-level conveyor versus $69 \%$ of the time when workers used the old conveyor with two levels (see Table III).

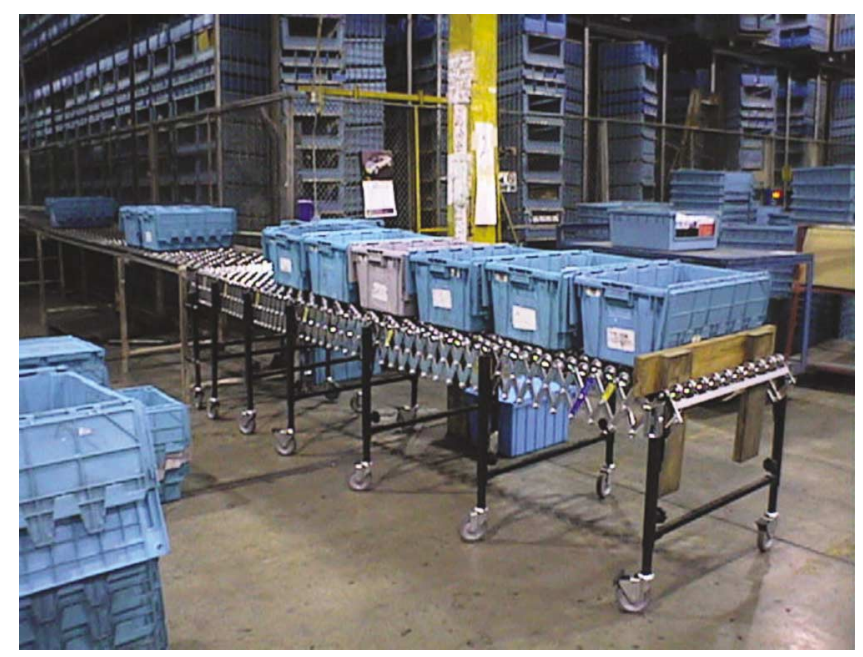

Fig. 12. The new single-level telescoping carousel output conveyor. 
Table III. Summary of Exposure Data for Case Study 3, Telescoping Conveyor

\begin{tabular}{|c|c|c|}
\hline & $\begin{array}{l}\text { Before intervention } \\
\text { was implemented }\end{array}$ & $\begin{array}{l}\text { After intervention was } \\
\text { implemented }\end{array}$ \\
\hline \multicolumn{3}{|c|}{ Weight of load lifted below design criterion based on } \\
\hline Back compression force & $4.5 \mathrm{~kg}$ & $\begin{array}{l}22.7 \mathrm{~kg} \text { (maximum } \\
\text { weight analyzed) }\end{array}$ \\
\hline Back strength capability & $20.4 \mathrm{~kg}$ & $\begin{array}{l}22.7 \mathrm{~kg} \text { (maximum } \\
\text { weight analyzed) }\end{array}$ \\
\hline Shoulder strength capability & $11.4 \mathrm{~kg}$ & $15.9 \mathrm{~kg}$ \\
\hline \multicolumn{3}{|l|}{ Percent of time in } \\
\hline Neutral torso postures & $69 \%$ & $96 \%$ \\
\hline Nonneutral torso postures & $31 \%$ & $4 \%$ \\
\hline Neutral shoulder postures & $76 \%$ & $95 \%$ \\
\hline Nonneutral shoulder postures & $6.5 \%^{a}$ & $5 \%$ \\
\hline
\end{tabular}

${ }^{a}$ Shoulder view obstructed for part of the analyzed work cycles.

\section{Shoulder}

When lifting totes from the high level of the old conveyor $(94 \mathrm{~cm}), 90 \%$ of males had the shoulder strength capabilities to handle totes up to $15.9 \mathrm{~kg}$ while $75 \%$ of females could handle loads up to $11.4 \mathrm{~kg}$. The new single-level conveyor presented totes at a height of $81.3 \mathrm{~cm}$. Consequently, less shoulder elevation was required to lift totes from the new conveyor. When lifting totes from the new conveyor, $90 \%$ of males had the shoulder strength capability to lift totes up to $18.2 \mathrm{~kg}$ and $75 \%$ of females had the shoulder strength capability to lift totes up to $15.9 \mathrm{~kg}$. The new conveyor did not greatly affect shoulder posture stresses (see Table III). A slight increase in neutral shoulder positions were observed when the new single-level telescoping conveyor was used.

\section{Worker Interviews}

No statistically significant differences between the pre- and postintervention ratings of work attributes were obtained. This may be due to several factors, but most importantly, the effect of other work tasks. Workers still spent a large amount of the work day consolidating parts at floor level and this required considerable forward torso bending. Interviews with three workers who used the old carousel conveyor system and four workers who used the new single-level conveyor revealed that worker ratings of lower back discomfort, knee discomfort, and strain associated with lifting objects all decreased.

\section{Implementation Hurdles/Fine Tuning}

Initially a fixed length output conveyor was used. During the first week of implementation trials, totes backed up on the conveyor and this caused a disruption in production. A telescoping conveyor alleviated that problem.

\section{Discussion}

The new single-level telescoping conveyor (vertical height of $81.3 \mathrm{~cm}$ ) reduced the trunk biomechanical and postural stresses and was recommended over the original two-level conveyor. The implementation issues were solved with the use of the adjustable length 
telescoping conveyor. However, the new conveyor did not address the ergonomic risk factors associated with other tasks that are still performed by these workers (e.g. consolidation at floor level, pushing stacks of totes, etc.).

\section{DISCUSSION}

Designing and implementing interventions to address risk factors of work-related musculoskeletal disorders is often presented as a straightforward process of identifying risk factors, developing interventions to address the risk factors, implementing the interventions and then re-evaluating the job (19). These case studies illustrate that process, include job analysis strategies and worker interviews during the analyses before and after the interventions were implemented, and also describe some of the implementation hurdles. Often, case study presentations focus on the "before" and "after" and do not include the iterative nature of the intervention design and implementation process. However, these case studies acknowledged the intervention design changes through the process. Additionally, these case studies represent both primary and secondary prevention (20). The interventions provided a reduction in exposure to work-related risk factors associated with musculoskeletal disorders. Consequently, restricted workers could be accommodated and future worker injury risk was reduced.

The design and implementation of ergonomic interventions must be developed within the framework of the entire manufacturing system. Consequently, production demands, safety concerns, work climate, and other work task demands must be considered. For example, production demands halted the use of the initial single-level conveyor since totes were backing up when the single-level fixed length conveyor was introduced. Substantial design change was needed to accommodate the production demands. The telescoping conveyor was a design that was not originally considered. Production demands also necessitated a change in identified interventions when a traditional lift/tilt table was introduced for packing parts into triwalls. Since the triwalls were frequently moved with pallet jacks, an alternative lift/tilt device was needed. Second, safety concerns enhanced the attractiveness of the selfelevating vehicle because it not only reduced risk factors associated with musculoskeletal disorders but also greatly decreased slip and fall potential since workers were no longer climbing ladders. Third, work climate was considered during intervention evaluation by including worker input to help assess the effectiveness of the intervention and to "tweak" the design of the self-elevating vehicle in order to accommodate the tickets and bags used as items are picked. Finally, other work task demands affect the risk of workers developing musculoskeletal disorders and none of these interventions addressed all task demands. A physically demanding task was addressed in all three case studies. For example, the telescoping conveyor greatly improved postures while lifting totes from the conveyor and greatly increased the acceptable tote weight. However, this task was only a small part of the overall work day and there were other physically demanding tasks (i.e. stacking and consolidating totes). In all of these case studies, additional modifications should be considered to reduce further the risk of workers developing musculoskeletal disorders.

\section{CONCLUSION}

These case studies illustrated ergonomic job analysis that included risk factor assessment and worker input. The iterative nature of intervention development was discussed as 
well as the implementation hurdles and additional enhancements that were still required. Despite the small number of participants and changes in worker health status were not recorded, a substantial decrease in worker exposure to risk factors of musculoskeletal disorders and a reduction in the risk of safety-related accidents were documented. In addition, worker interviews revealed worker acceptance and agreement that the targeted risk factors were reduced. Future intervention evaluations should document worker health and/or symptom changes as well as changes in risk factor exposure. The limitations of production demands, funding for interventions, and workforce changes are all variables that greatly affect a "controlled research study."

\section{ACKNOWLEDGMENT}

This project was funded in whole by joint funds from the UAW-Daimler-Chrysler National Joint Committee on Health and Safety. The results presented herein represent the conclusions and opinions solely of the authors. Its publication does not necessarily imply endorsement by the International Union UAW, or Daimler Chrysler.

\section{REFERENCES}

1. United States Department of Labor. Occupational Safety and Health Administration: "Ergonomics Program; Final Rule," 29 CFR Part 1910. Fed Regis 2000; 65: 68261-68870 (Referring to data reported to the BLS in 1997.)

2. Bureau of Labor Statistics. Table S18. Rate and number of cases of disorders associated with repeated trauma by industry, 2001 and Table S11. Highest incidence rates of disorders associated with repeated trauma, private industry, 2001. Retrieved October 10, 2003, from http://www.bls.gov/data/

3. Westgaard RH, Winkel J. Ergonomic intervention research for improved musculoskeletal health: A critical review (Review article). Int J Ind Ergon 1997; 20: 463-500.

4. Aarås A. The impact of ergonomics intervention on individual health and corporate prosperity in a telecommunications environment. Ergonomics 1994; 37: 1679-1696.

5. Grandjean E, Hünting W, Pidermann M. VDT work-station design: Preferred settings and their effects. Hum Factors 1983; 25: 161-175.

6. Kadefors R, Engström T, Petzell J, Sundström L. Ergonomics in parallelized car assembly: A case study with reference also to productivity aspects. Appl Ergon 1996; 27: 101-110.

7. Keyserling WM, Brouwer M, Silverstein BA. The effectiveness of a joint labor-management program in controlling awkward postures of the trunk, neck, and shoulders: Results of a field study. Int J Ind Ergon 1993; 11: 51-65.

8. Lifshitz YR, Armstrong TJ, Seagull FBJ, Smith TD. The effectiveness of an ergonomics program in controlling work related disorders in an automotive plant-A case study. In: Quéinnec Y, Daniellou F, eds. Designing for everyone: Proceedings of the 11th Congress of the International Ergonomics Association, Vol. 1. London: Taylor \& Francis, 1991, pp. 323-325.

9. Kukkonen R, Lammi S, Antti-Poika M. Effects of dynamic muscular exercise and working habits on neck/shoulder pain among hospital workers. In: Quéinnec Y, Daniellou F, eds. Designing for everyone: Proceedings of the 11th Congress of the International Ergonomics Association, Vol. 1. London: Taylor \& Francis, 1991, pp. 135-137.

10. Verbeek J. The use of adjustable furniture: Evaluation of an instruction programme for office workers. Appl Ergon 1991; 22: 179-184.

11. Videman T, Rauhala H, Asp S, Linstrom K, Cederceutz G, Kämppi M, Tola S, Troup JDG. Patient-handling skill, back injuries, and back pain. An intervention study in nursing. Spine 1989; 14: 148-156.

12. Keyserling WM, Ulin SS, Lincoln AE, Baker SP. Using multiple information sources to identify opportunities for ergonomic interventions in automotive parts distribution: A case study. Am Ind Hygiene Assoc J 2003; 64: 690-698.

13. The Regents of the University of Michigan. $3 D$ Static Strength Prediction Program ${ }^{T M}$ (Computer program). Ann Arbor, MI: The University of Michigan, Center for Ergonomics.

14. Waters TR, Putz-Anderson V, Garg A, Fine LJ. Revised NIOSH equation for the design and evaluation of manual lifting tasks. Ergonomics 1993; 36(7): 749-776. 
15. Anderson CK. A biomechanical model of the lumbosacral joint for lifting activities. PhD Dissertation, The University of Michigan, Ann Arbor, MI, 1983.

16. National Institute for Occupational Safety and Health (NIOSH). Work Practices Guide for Manual Lifting. DHHS (NIOSH) Publication No. 81-122.

17. Keyserling WM. A computer-aided aystem to evaluate postural stress in the workplace. Am Ind Hyg Assoc J 1986; 47: 641-649.

18. Neter J, Wasserman W, Kutner MH. Applied Linear Statistical Models, 2nd edn. Homewood, IL: Richard D. Irwin, 1985.

19. Ulin SS, Armstrong TJ. A Strategy for evaluating occupational risk factors of musculoskeletal disorders. J Occup Rehabil 1992; 2(1): 35-50.

20. Loisel P, Gosselin L, Durand P, Lemaire J, Poitras S, Abenhaim L. Implementation of a participatory ergonomics program in the rehabilitation of workers suffering from subacute back pain. Appl Ergon 2001; 32: 53-60. 